\section{Elements of Optical Mineralogy}

An Introduction to Microscopic Petrography. By Prof. Alexander N. Winchell, with collaboration of Prof. Horace Winchell. Fourth edition. Part 2 : Descriptions of Minerals, with Special Reference to their Optical and Microscopical Characters. Pp. xvi 551. (New York: John Wiley and Sons, Inc.; London: Chapman and Hall, Ltd., 1951.) 100s. net.

$\mathrm{T}$ HE fourth edition of Part 2 of $A$. N. and $H$. Winchell's "Elements of Optical Mineralogy" follows the third after an interval of eighteen years. During this period important developments in mineralogy have resulted from the intensified X-ray study of crystals, leading not only to increased knowledge of crystal structures, but also to a better understanding of variations in mineral composition, and to a revised classification.

As in previous editions, the book includes descriptions of all minerals the optical properties of which are sufficiently well known to permit diagnosis by means of a microscope. In bringing the work up to date, emphasis has been laid especially on the properties which serve this purpose; but details of the crystal structure of individual minerals as determined by $\mathrm{X}$-rays are also given.

In the third edition, while the primary classification was chemical, the silicates were subdivided, so far as the knowledge of the time permitted, into groups on a structural basis. This system has been followed in the fourth edition; but the increased knowledge has permitted its extension to include within these groups all silicate minerals, with the proviso that the inclusion of certain minerals in particular groups is tentative. Opportunity has also been taken to bring into use the group names, tectosilicate, phyllosilicate, etc., proposed since the last edition.

This is a standard work, and it is regrettable that the increased cost of book production in the United States, and the current rate of exchange, necessitate a price that must put the book out of reach of many potential buyers.

\section{Industrial Solvents}

By Ibert Mellan. Second edition. Pp. $x+758$. (New York: Reinhold Publishing Corporation; London: Chapman and Hall, Ltd., 1950.) 96s. net.

T $\mathrm{N}$ the eleven years which have elapsed between the 1 publication of the first and second editions of this work, many new solvents have been discovered or developed for commercial use, and measurements of physical properties have multiplied. It is not surprising, therefore, to find that the size of the volume has inereased by more than 50 per cent.

The first 200 pages deal with solution and general properties of solvents in a manner which may appear unorthodox to physical chemists, unless they realize that the subject-matter is concerned mainly with solvents and their uses in the paint and varnish industry. A bad fault occurring here and throughout the book is the presentation of data on solubility, viscosity and rates of evaporation without any mention of temperature. Many figures given in this part are repeated later, and it is suggested that a great improvement would result from a thorough revision and drastic curtailment.

The remainder of the book contains a vast amount of information of most diverse nature regarding the properties and uses of some four hundred liquids and their mixtures. Numerous commercial solvents are included and their composition indicated. Some of the data recorded appear to be of little value, while an item of real interest; the price of the solvents, has been omitted. Minor criticisms apart, however, there is no doubt that this volume, with its wealth of information collected from sources which are in many cases inaccessible to the average reader, must be regarded as indispensable to all those whose work involves the use of organic liquids. H. E. WATSON

\section{The Technology and Chemistry of Alkaloids}

By Frank E. Hamerslag. Pp. viii +319. (New York: D. Van Nostrand Co., Inc.; London: Macmillan and Co., Ltd., 1950.) 48s. $6 d$. net.

THIS book is primarily intended to assist those engaged in the manufacture of alkaloids. It is therefore principally, but far from exclusively, concerned with processes of isolation (or synthesis) and purification. Following a brief description of general procedures and technical equipment, the commercially practicable alkaloids are discussed in turn, either as individuals or as related groups, in eighteen chapters. Each chapter contains some discussion of the structural chemistry, the natural sources, the pharmacological properties and the means of identification of the appropriate alkaloids, in addition to a description of the manufacturing methods used. It is probably in this last respect that the main value of the book emerges, for the author is able to draw upon his personal experience in order to evaluate procedures, to give practical advice and to make specific recommendations. The detailed descriptions given of the methods of isolating individual alkaloids certainly merit the attention of all who have occasion to undertake these operations. The book is equipped with a comprehensive index and the text is liberally supplied with references to the original literature.

The Thought of C. S. Peirce

By Prof. Thomas A. Goudge. Pp. xiv +360. (Toronto: University of Toronto Press; London: Oxford University Press, 1950.) 40s, net.

THE life of Charles Sanders Peirce (1839-1914) presents the world of scholarship with a problem at once profound and fascinating. Prof. Goudge, in writing this distinguished book, sets out to explain why this should be, and what can be learnt from it. Essentially, Peirce was an example of ambivalence; he was capable of an enviable analytic power at times (perhaps mostly) overwhelmingly naturalistic, at other times completely transcendental. If a conclusion is permissible regarding a life so fruitful and yet lived so dangerously, it is that his naturalism triumphed in his mind, his transcendentalism in his heart. This entailed a certain rigidity of partition between theory and practice, exemplified by the extremely abstract character of his thought when functioning as a philosopher or logician, alongside a thoroughly competent, almost mundane, affection for experimental chemistry, in which subject he graduated summa cum laude. When to all this is added more than a touch of the poet and the mystic (making him accord to æsthetics, for example, an exalted place in his hierarchy), it is clear with what a unique mind we are confronted.

Prof. Goudge shows a sure touch: he lets the restless intellect of Peirce shine through, without the interposition of a biographical screen. An excellent memoir is the result, full without being repetitious, understanding yet critical. F. I. G. RAWLINS 